\title{
ADSORPTION OF CR-(VI) FROM AQUEOUS ENVIRONMENT USING NEEM LEAVES POWDER
}

\author{
Rahul N. Jain ${ }^{1}$, S. B. Patil ${ }^{2}$, D. S. Lal ${ }^{3}$ \\ ${ }^{1}$ ME (Environmental Engineering), Department of Civil Engineering, S.S.B.T. 's COET, Bambhori- Jalgaon, \\ Maharashtra \\ ${ }^{2}$ Assistant Professor, Department of Civil Engineering, S.S.B.T. 's COET, Bambhori- Jalgaon, Maharashtra \\ ${ }^{3}$ Assistant Professor, Department of Civil Engineering, RCPIT, Shirpur Maharashtra
}

\begin{abstract}
This study is aimed at utilizing Neem Leaves powder as low cost adsorbent material for removal of Cr-(VI) from aqueous solution. Adsorption is an important process used for removal of colour, odour, turbidity, metal ions and reduction of COD. In adsorption, the solute present in dilute concentration in liquid or gas phase is extracted by contacting with suitable solid adsorbent so that the transfer of the component first takes place on the surface of solid and then into the pore of the solid. Neem Leaves powder Adsorbent used in present study is prepared at Laboratory scale which is very effective to remove chromium from its aqueous solution. This study describes the detailed experimental procedure to obtain Adsorption Equilibrium and the Effect of various parameters such pH, agitation time, initial metal ion concentration \& adsorbent doses on batch technique.
\end{abstract}

Keywords: Hexa-valent Chromium, Neem Leaf Powder, Adsorption, Batch process, UV-Vis Spectrophotometer.

\section{INTRODUCTION}

Due to increased urbanization as well as industrialization, generation of large amount of toxic contaminants especially heavy metals are to be produced. These received widespread attention because of their persistent nature, toxicity, carcinogenicity or mutagenicity even at very low concentrations. Among these heavy metals chromium is more toxic. Chromium ion in industrial wastewater occurs in two forms; trivalent $\mathrm{Cr} 3+$ and hexa-valent $\mathrm{Cr} 6+$. The increase in concentration levels of heavy metals in the environment particularly in water is a cause for concern. The major contributor for this rise in the concentration level is in the extensive development of heavy \& manufacturing industries that uses metals \& related compounds.

Discharge of treated industrial wastewater containing metal ions such as nickel, lead, copper, zinc, chromium and aluminium are common in nearby water sources like river. This may result in affecting the quality of aquatic \& human life. Therefore, the removal of heavy metals from wastewater is essential.

\subsection{Sources of $\mathrm{Cr}$-(VI)}

Main sources of chromium-(VI) pollution are 1) Mining industry 2) Leather Tanning industry 3) Cement industry 4) Electroplating industry 5) Production of steel and other metal alloys industry 6) Photographic material and corrosive paints 7) Nuclear Power-plants 8) Textile industries. Chromium is the naturally occurring element which is found in the volcanic-ash, volcanic-gases, soil and rocks (Abbasi and Soni, 1985). Chrome plating, leather tanning, combustion of natural fuels (gas, oil, coal), catalysts, fertilizers, dye manufacturing industries, battery making, printers, emission from cooling towers, air condensers and incineration of sewage sludge, municipal refuse and other solid wastes, are the anthropogenic sources of chromium emission in the environment (Faisal and Hasnain, 2004). More than 1, 70,000 metric tonnes of chromium wastes are discharged annually in environment as a result of industrial and manufacturing activities (Abassi et al, 1998). The leather industry is the major cause for the high influx of chromium to the biosphere, accounting for $40 \%$ of the total industrial use (Baruhart, 1997). Chromium exists in food, air, water and soil, mostly in the trivalent form. It is only as a result of human activities that substantial amounts of $\mathrm{Cr}$ (VI) become present in environment. $\mathrm{Cr}$-(III) is comparatively insoluble while $\mathrm{Cr}-(\mathrm{VI})$ is quite soluble and is readily leached from soil to groundwater or surface water.

\subsection{Cr-(VI) Metal Impacts on Health}

The hexa-valent form is 500 times more toxic than the trivalent (Kowalski, 1994). It is toxic to micro-organisms, plants, animals and humans. Human toxicity includes lung cancer as well as kidney, liver, and gastric damage (US Department of Health and Human Services, 1991; CieslakGolonka, 1995). The tanning process is one of the largest polluters of chromium all over the world. Most of the tanneries in India adopt the chromium tanning process because of its processing speed, low costs, and light color of leather and greater stability of the resulting leather.

In the chromium tanning process, the leather takes up only $60-80 \%$ of applied chromium, and the rest is usually discharged into the sewage system causing serious environmental impact. Chromium ion in liquid tanning wastes occurs mainly in trivalent form, which gets further oxidized to hexa-valent $\mathrm{Cr}-(\mathrm{VI})$ form, due to the presence of 
organics. For nearly a century, heavy metal-laden wastewater discharged from industries, are posing a serious challenge to environmental, public health, scientists and Engineers. Numerous investigations on effects of heavy metal on environment and human have been carried out. Unlike organic pollutants, which in most cases can be destroyed, heavy metal discharged into environment tend to persist indefinitely, circularly and eventually throughout the food chain thus causing a series of threats to human and organisms (Cooke et al, 1990; Deniseger et al, 1990;Sag et al, 1995b; Chua and Hua, 1996). Even if the heavy metal ions in water present in dilute, undetectable quantities, their recalcitrance and consequent persistence in water bodies imply that through natural processes, such as biomagnification, concentrations may become elevated to such an extent that they begin exhibiting toxic characteristics (Atkinson et al, 1998).

\subsection{Permissible Limits of $\mathrm{Cr}$-(VI)}

The maximum levels permitted in waste-water are $5 \mathrm{mg} / \mathrm{L}$ for trivalent chromium and $0.05 \mathrm{mg} / \mathrm{L}$ for hexavalent chromium (Acar and Malkoc, 2004). With this limit, it is essential for industries to treat their effluents to reduce the Cr to acceptable levels.

The Ministry of Environment and Forest (MOEF), Government of India has set mini-mal national standards (MINAS) of $\mathbf{0 . 1} \mathbf{~ m g} / \mathbf{L}$ for safe discharge of effluent containing $\mathrm{Cr}(\mathrm{VI})$ in surface water and in potable water is $0.05 \mathrm{mg} / \mathrm{L}$.

\section{BATCH ADSORPTION EXPERIMENT} ANALYSIS

Study reports the use of Neem leaves powder as a low cost adsorbent and investigation of various parameters such as $\mathrm{pH}$, metal ion concentration, adsorbent dose and contact time by using batch adsorption technique.

1. Using Neem Leaves adsorbents in $250 \mathrm{ml}$ stopper conical flask containing $100 \mathrm{ml}$ of $\mathrm{Cr}$ (VI) solution batch adsorption were carried out. $\mathrm{pH}$ of the solution adjusted by adding $\mathrm{H}_{2} \mathrm{SO}_{4}$ or $\mathrm{NaOH}$ or HCL solution as required. Then the flasks were shaken for the desired contact time.

2. The time required to reach the equilibrium was estimated by withdrawing conical flask containing treated solution at regular intervals of time. The content flasks were filtered through filter paper (Whatman no.1).

3. UV-visible Spectrophotometer employed to determine the remaining $\mathrm{Cr}$ (VI) concentration in the sample solution using 1, 5-diphenylcarbazide method as laid down in standard methods for examination of water and wastewater, APHA, AWWA, WEF, 1998 edition.

4. The removal percentage $(\mathrm{R} \%)$ of chromium was calculated for each run by following expression:
$\mathrm{C}_{\mathrm{i}^{-}}$initial concentration of chromium in the solution. $\mathrm{C}_{\mathrm{e}}$ - final concentration of chromium in the solution

\section{CHEMICALS \& INSTRUMENTS}

\subsection{Chemicals/ Materials Required}

1. Distilled water/ De-ionized water

2. Standard buffer solution-For $\mathrm{pH}$ meter calibration

3. $\mathrm{H}_{2} \mathrm{SO}_{4} / \mathrm{NaOH} / \mathrm{HCL}-$ For adjusting $\mathrm{pH}$ of Solution

4. 1,5-Diphenyl Carbazide (DPC)

5. Neem leaves

6. Potassium chromate/ Potassium dichromate

\subsection{Equipments Required}

- $\quad \mathrm{pH}$ meter/ $\mathrm{pH}$ paper

- UV-VIS Spectrophotometer

- $250 \mathrm{ml}$ Stopper Conical flask

- What-man Filter Paper

- Muffle furnace

- Digital Weighing Balance

- Glass Beakers

- Measuring Cylinders

- $\quad$ Burettes \& Pipettes

\section{EXPERIMENTAL METHOD}

\subsection{Adsorbent Preparation}

1. Neem leaves were collected from local nearby area \& washed with several times to remove dust particles.

2. Adsorbents were oven dried to remove the adherent moisture content.

3. Dried leaves were crushed with domestic mixture.

4. Adsorbent in a powder form was obtained. After drying, adsorbent sieved to obtain particle size of $250-350 \mu \mathrm{m}$ prior to being used for adsorption studies.

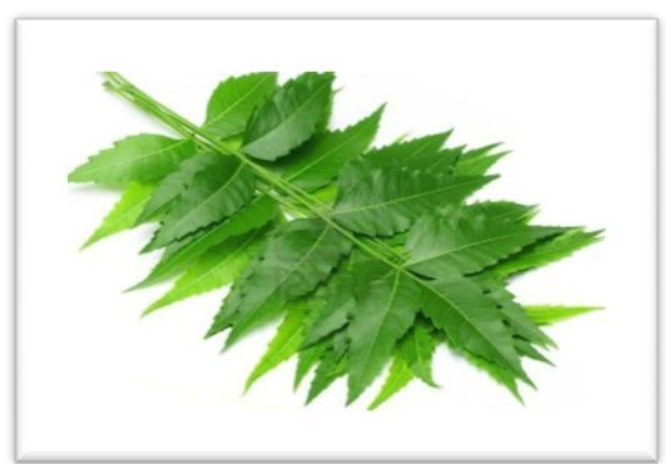

\subsection{Preparation of Standard CR-(VI) Solution}

The stock solution containing $1000 \mathrm{mg} / \mathrm{L}$ of $\mathrm{Cr}-(\mathrm{VI})$ was prepared by dissolving $2.828 \mathrm{~g}$ of $\mathrm{A}$. R. grade potassium dichromate $\left(\mathrm{K}_{2} \mathrm{Cr}_{2} \mathrm{O}_{7}\right)$ in $1000 \mathrm{ml}$ double-distilled water. Required initial concentrations of $\mathrm{Cr}$-(VI) standards were prepared by appropriate dilution of the stock $\mathrm{Cr}$-(VI) solution.

$\mathrm{R}(\%)=\left[\left(\mathrm{C}_{\mathrm{i}}-\mathrm{C}_{\mathrm{e}}\right) / \mathrm{C}_{\mathrm{i}}\right] \times 100$ Where, 


\subsection{Determination of Maximum Absorptive}

\section{Wavelength for Operation}

Absorbances were recorded at different wavelengths by using UV-vis Spectrophotometer. Up to certain wavelength absorption increases and then decreases, at the point where the $\%$ absorption is maximum that point is considered as maximum wavelength of operation.

\subsection{Construction of Standard Calibration Curve for}

\section{Chromium}

For this purpose, solution of chromium of different concentrations were prepared and their absorbance recorded by using UV Spectrophotometer. The Spectrophotometer is set to Zero absorbance with the reference solution (Distilled water) and then the absorbance of standard solution was measured. With the help of these Reading standard calibration curve plotted between Absorbance and standard chromium solution of various concentrations.

Table-1 Standard Calibration Curve For $\mathrm{Cr}^{+6}$

\begin{tabular}{|l|l|l|l|}
\hline $\begin{array}{l}\text { Concentration } \\
(\mathrm{ppm})\end{array}$ & Absorbance & $\begin{array}{l}\text { Concentration } \\
(\mathrm{ppm})\end{array}$ & Absorbance \\
\hline 1 & 0.1 & 6 & 0.5 \\
\hline 2 & 0.19 & 7 & 0.64 \\
\hline 3 & 0.32 & 8 & 0.7 \\
\hline 4 & 0.38 & 9 & 0.87 \\
\hline 5 & 0.48 & 10 & 0.99 \\
\hline
\end{tabular}

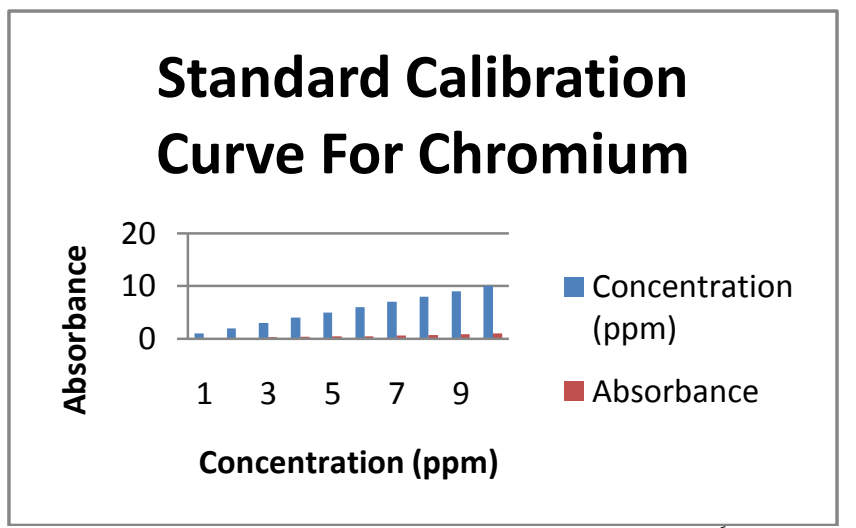

Fig. 1- Standard Calibration Curve For $\mathrm{Cr}^{+6}$

Graph shows as chromium concentration increases absorbance also increases. Curve to be used as a standard curve for determining concentration of an unknown $\mathrm{Cr}$ solution by observing Absorbance with the help of UV-VIS Spectrophotometer.

\subsection{RESULTS \& DISCUSSIONS}

\subsection{Effect of pH}

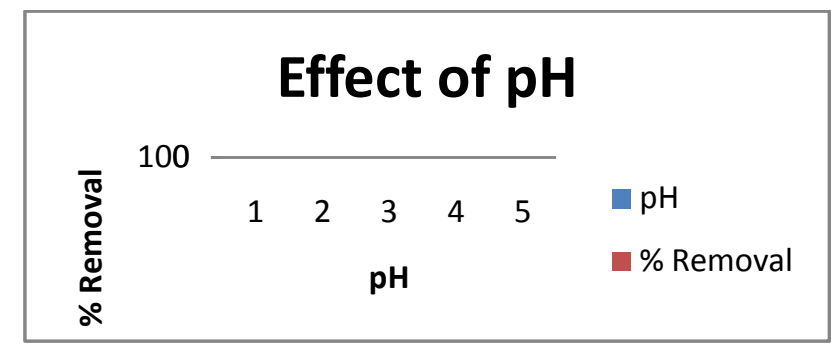

Fig.2- Effect of $\mathrm{pH}$ on removal of $\mathrm{Cr}(\mathrm{VI})$ ion

$\mathrm{pH}$ affects the solubility of chromium ion to a great extent. The $\mathrm{pH}$ of aqueous solution is the controlling factor in the adsorption process; hence it become necessary to determine at what $\mathrm{pH}, \max$ adsorption will takes place. Percentage removal of Chromium goes on decreasing with increase in $\mathrm{pH}$ values. The maximum removal efficiency was $67.5 \%$ at $2 \mathrm{pH}$ value. The Chromium removal was higher at lower $\mathrm{pH}$ values.

\subsection{Effect of Contact Time}

Graph shows that Removal efficiency of $\mathrm{Cr}$-(VI) ion increases with respect to increase in contact time (in min.) of adsorbent.

\section{Effect of Contact Time}

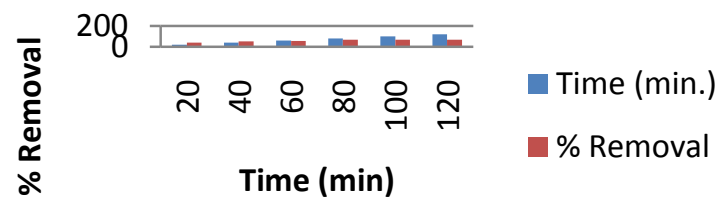

Fig.3-Effect of contact time on removal of $\mathrm{Cr}$ - (VI) ion

\subsection{Effect of Initial Metal Ion Concentration}

It was observed that the activity of adsorbent material falls sharply with an increase in initial concentration of chromium ion. The max Cr removal efficiency for all the set of optimized parameter was found to be $98 \%$ for Neem Leaves at initial concentration of $30 \mathrm{mg} / 100 \mathrm{ml}$.

\section{Effect of Concentration}

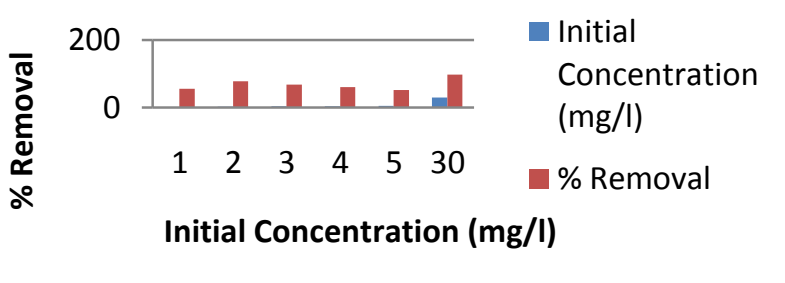

Fig.4-Effect of initial concentration on removal of $\mathrm{Cr}-(\mathrm{VI})$ ion 


\subsection{Effect of Adsorbent Dose}

It can be seen that the rate of the removal of chromium ions increases with an increase in the amount of adsorbent dosage (in gm). The amount of adsorbent dose varies from $2 \mathrm{gm} / 100 \mathrm{ml}$ to $10 \mathrm{gm} / 100 \mathrm{ml}$. The removal efficiency is maximum at dose of $8 \mathrm{gm} / 100 \mathrm{ml}$ which is up to $85 \%$.

\section{Effect of Adsorbent Dose}

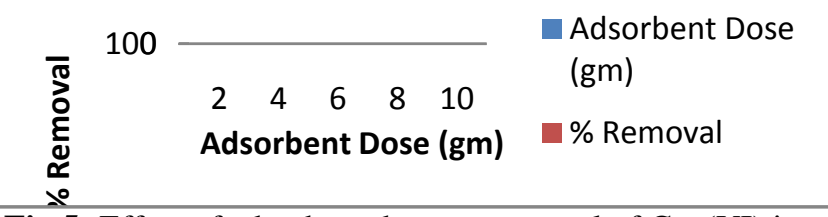

Fig.5- Effect of adsorbent dose on removal of Cr- (VI) ion

\section{CONCLUSIONS}

Maximum removal efficiency achieved up to $85 \%$ for biosorbent prepared from Neem Leaves at the optimum values of parameters. Percentage adsorption decreases with increase in initial metal ion concentration \& increases with increase in adsorbent dosage \& contact time. Study clearly shows that Neem leaves powder which is cheap and abundantly available can be used as an effective adsorbent for removal $\mathrm{Cr}-(\mathrm{VI})$ from effluent.

Also adopted and used widely in industries, not only to minimize cost but also to improve profit. In addition to this, living organisms and surrounding environment will also be benefited from the decrease or elimination of the potential toxicity created due to heavy metal like $\mathrm{Cr}$-(VI). Maximum adsorption occurs at $\mathrm{pH}$ value- 2 hence, it is taken as optimum $\mathrm{pH}$ value for further experiments.

\section{REFERENCES}

[1]. Parineeta Pandhram, Shubhangi Nimbalkar, 'Adsorption of Chromium from Industrial Waste Water' By Using Neem Leaves as a Low Cost Adsorbent, International Journal of Chemical and Physical Sciences IJCPS Vol. 2, Special Issue - March 2013 (ISSN:2319- 6602).

[2]. N. M. Rane, Dr. R. S Sapkal, Dr. V. S. Sapkal, M. B. Patil and S. P. Shewale," Use of Naturally available low cost adsorbent for removal of $\mathrm{Cr}(\mathrm{VI})$ from waste water", International Journal of Chemical Sciences and Applications ISSN 0976-2590.Vol 1, Issue 2, Dec-2010, pp 65-69.

[3]. K. Srinivas Raju, and S.V. Naidu, 'A Review On Removal Of Heavy Metal Ions From Wastewater By Rice Husk As An Adsorbent'Journal of Chemical, Biological and Physical Sciences, February 2013- April 2013, Vol. 3, No. 2, 602-606, E- ISSN: $2249-1929$.

[4]. Tarun Kumar Naiya, Biswajit Singha and Sudip Kumar Das, 'FTIR Study for the Cr(VI) Removal from Aqueous Solution Using Rice Waste'2011 International Conference on Chemistry and Chemical Process IPCBEE vol.10 (2011) (C) (2011) IACSIT Press, Singapore.

[5]. K. Gopalakrishnan, V. Manivannan And T. Jeyadoss, Comparative Study on Biosorption of $\mathrm{Zn}(\mathrm{II}), \mathrm{Cu}(\mathrm{II})$ and
Cr(VI) from Textile Dye Effluent Using Sawdust and Neem Leaves Powder.

[6]. Gopalakrishnan S., Kannadasan T., Velmurugan S., Muthu S. and Vinoth Kumar P., Biosorption of Chromium (VI) from Industrial Effluent using Neem Leaf Adsorbent. Research Journal of Chemical Sciences Vol. 3(4), 48-53, April (2013).

[7]. Biswajit Singha, Tarun Kumar Naiya, Ashim Kumar Bhattacharya, Sudip Kumar Das, Cr(VI) Ions Removal from Aqueous Solutions Using Natural Adsorbents-FTIR Studies Journal of Environmental Protection, 2011, 2, 729735.

[8]. Biswajit Singha and SudipKumar Das, Cr(Vi) Adsorption - Mechanistic Approach For Biosorption From Aqueous Solutions, Paper presented in International Conference on Environment, Energy and Development (from Stockholm to Copenhagen and beyond) December 10 - 12, 2010, Sambalpur University.

[9]. N. M. Rane, Dr. R. S Sapkal, Dr. V. S. Sapkal, M. B. Patil and S. P. Shewale," Use of Naturally available low cost adsorbent for removal of $\mathrm{Cr}(\mathrm{VI})$ from waste water", International Journal of Chemical Sciences and Applications ISSN 0976-2590. Vol 1, Issue 2, Dec-2010, pp 65-69.

[10]. Mohmmad subhan, dr. Pardeep, study to adsorbent of rice husk \& saw dust (agriculture waste \& timber waste), International Journal of Research in Science And Technology, ISSN: 2249-0604, (IJRST) 2011, Vol. No. 1, Issue No. III, Oct-Dec.

\section{BIOGRAPHIES}

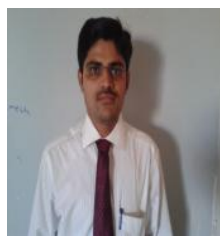

Rahul N. Jain received his Bachelor of Civil Engineering from J.T.M. COE, Faizpur- NMU, Jalgaon. He is currently pursuing M.E. in Environmental Engineering from S.S.B.T.'s COET, Bambhori, Jalgaon.

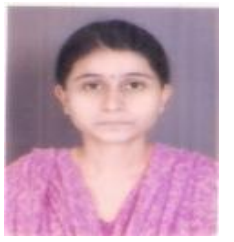

Mrs. S.B. Patil is working as Assistant Professor in Civil Engineering Department of S.S.B.T's COET, Bambhori, Jalgaon (NMU, Jalgaon). She did her masters in 2010\& joined as a Lecturer. Also, published a paper in an International journal of repute to her credit.

Prof. D .S. Lal is working as assistant professor in civil engineering Department since 2007 